\title{
INFLUÊNCIA DA PODA DE RENOVAÇÃO E CONTROLE DA FERRUGEM NAS RESERVAS DE CARBOIDRATOS E PRODUÇÃO DE PESSEGUEIRO PRECOCE ${ }^{1}$
}

\author{
JOÃO PAULO CAMPOS DE ARAUJO², ALESSANDRO RODRIGUES ${ }^{2}$, \\ JOÃO ALEXIO SCARPARE FILHO ${ }^{3}$, RAFAELPIO ${ }^{4}$
}

RESUMO- Este trabalho objetivou verificar a influência da poda de renovação e controle da ferrugem nas reservas de carboidratos não-estruturados em ramos e raízes do pessegueiro cultivar Flordaprince, bem como o possível efeito na produção e qualidade dos frutos. O trabalho foi conduzido no Departamento de Produção Vegetal da ESALQ-USP, em Piracicaba. O delineamento experimental utilizado foi em sete blocos ao acaso, constando de três tratamentos, sendo cada parcela constituída de quatro plantas. O tratamento 1 consistiu na realização da poda de renovação que foi executada 45 dias após a colheita, no mês de outubro de 2003 . No tratamento 2, não se realizou a poda de renovação, e foi feito o controle da ferrugem. No tratamento 3, não foi realizada a poda de renovação, tampouco o controle da ferrugem, ocasionando desfolha antecipada. Os dados foram submetidos às análises de variância e à comparação das médias, pelo teste de Tukey. O espaçamento utilizado foi de 3,0 por 1,2 m, correspondendo a 2.777 plantas ha-1 $^{-1}$. As plantas foram conduzidas em sistema de líder central e receberam as práticas culturais normalmente utilizadas. Foram coletadas amostras de raízes e ramos que foram secos, moídos e submetidos à análise de laboratório para verificação dos teores de carboidratos não-estruturados. Ocorre flutuação na concentração de carboidratos solúveis nas raízes e nos ramos de acordo com a época da coleta, sendo que os teores de carboidratos solúveis nas raízes são sempre superiores àqueles encontrados nos ramos. O tratamento 2 apresentou maior produção de frutos e maior número de frutos por planta. Não houve efeito dos tratamentos nos aspectos qualitativos dos frutos, como diâmetro, comprimento, coloração e teor de sólidos solúveis.

Termos para indexação: Prunus persica (L.) Batsch, controle fitossanitário, qualidade de frutos.

\section{INFLUENCE OF THE RENEWAL PRUNING AND CONTROL OF THE RUST IN THE CARBOHYDRATE RESERVES AND PRODUCTION OF PRECOCIOUS PEACH TREE}

\begin{abstract}
This work aimed to verify the influence of the renewal pruning and control of the rust in the reserves of non structured carbohydrates in branches and cultivar peach tree roots Flordaprince, as well as the possible effect in the production and quality of the fruits. The work was conducted in the Vegetable Production Department at ESALQ-USP, in Piracicaba. The used experimental design was in seven random blocks, consisting of three treatments, being each part composed by four plants. The treatment 1 consisted in the renewal pruning that was done 45 days after the harvest, in October 2003. In the treatment 2, the renewal pruning was not accomplished, but the rust control was done. In the treatment 3 neither the renewal pruning nor the rust control was accomplished, making the leaves fall with anticipation. The data was submitted to the variance analyses and to the comparison of the averages by Tukey's test. The spacing pattern was of 3,0 for $1,2 \mathrm{~m},(2777$ plants/ha). The plants were conducted in the central leader's system and they received the usually cultural practices. Samples of roots and branches were collected and they were dried, crushed and submitted to the laboratory analysis to check the non structured carbohydrate contents. There is a float in the concentration of soluble carbohydrates in the roots and in the branches according to the harvest period, and the contents of soluble carbohydrates in the roots are always higher than in the ones found in branches. The treatment 2 showed larger production of fruits and larger number of fruits per plant. There was no effect of the treatments in the qualitative aspects of the fruits, such as diameter, length, coloration and content of soluble solids.
\end{abstract}

Index terms: Prunus persica (L.) Batsch, pest control, quality of fruits.

${ }^{1}$ (Trabalho 177-07).Recebido em: 26-07-2007. Aceito para publicação em: 29-02-2008

${ }^{2}$ Eng $^{\circ}$. Agrônomo, MSc, Doutorando do curso de Fitotecnia da Escola Superior de Agricultura "Luiz de Queiroz" - ESALQ/USP. jp.campos@uol.com.br e arodrigu@esalq.usp.br.

${ }^{3}$ Eng $^{\circ}$. Agrônomo, Doutor, Professor do Departamento de Produção Vegetal da Escola Superior de Agricultura "Luiz de Queiroz" - ESALQ/USP. jascarpa@esalq.usp.br.

${ }^{4} E_{n}{ }^{\circ}$. Agrônomo, Doutor, Professor Adjunto da Universidade Estadual do Oeste do Paraná (UNIOESTE), Rua Pernambuco, n 1777, C.P.1008, Centro, 85960-000, Marechal Cândido Randon-PR.rafaelpio@hotmail.com. 


\section{INTRODUÇÃO}

A cultivar Flordaprince de pessegueiro destaca-se no Estado de São Paulo pela alta produtividade, aspecto atraente dos frutos e apresenta ciclo de 85 a 90 dias (Ojima et al., 1983). Portanto, trata-se de uma cultivar precoce, de ciclo curto, porém não apresenta tamanho adequado dos frutos.

De maneira geral, a produção de pêssego em São Paulo está direcionada ao mercado in natura, ou seja, como frutos de mesa. Logo, a qualidade do fruto é de vital importância para que atinja melhor cotação no mercado consumidor, resultando em remuneração mais satisfatória ao produtor.

A precocidade de maturação pode ser considerada o principal fator de sucesso econômico ao persicultor paulista, existindo uma demanda muito grande por novas técnicas de manejo que possibilitem a melhoria da qualidade dos frutos. Várias estratégias vêm sendo pesquisadas em segmentos do processo produtivo, desde o plantio até a colheita, com o intuito de aumentar a produtividade e, sobretudo, melhorar a qualidade dos frutos.

A poda de renovação, segundo Nienow (1997), demonstrou ser um método eficiente para aumentar a área produtiva das plantas, bem como para retardar o desfolhamento e a quebra de dormência natural, evitando o florescimento nos meses de verão. Ainda, segundo esse autor, a poda de renovação proporcionou a obtenção de maior número de frutos por planta. Essa operação é realizada no primeiro mês após a colheita com a poda de todos os ramos, que produziram ou não, reiniciando o crescimento vegetativo e a diferenciação das gemas para a produção da safra seguinte.

Francisconi et al. (1996) pesquisaram o efeito da intensidade da poda verde em relação à coloração da fruta e constataram que os frutos das plantas podadas com desbaste de $75 \%$ dos ramos do ano foram mais coloridos, seguido pelos das plantas com desbaste de $50 \%$. O desbaste de $25 \%$ dos ramos não melhorou a coloração dos frutos, em comparação com os das plantas-testemunha.

Nas plantas de modo geral, durante o crescimento vegetativo, a maioria dos carboidratos é transportada para as raízes e folhas jovens, enquanto, após o florescimento, os carboidratos são direcionados prioritariamente para os frutos, tubérculos e raízes de reservas (Roitsch et al., 2003).

Segundo Nienow (1997), pode ocorrer competição por nutrientes entre o crescimento vegetativo e as gemas floríferas, uma vez que, no caso do pessegueiro, o crescimento vegetativo ocorre concomitantemente à formação dos frutos.

$\mathrm{Na}$ família Rosaceae, a maior parte do carbono fixado na fotossíntese é armazenado na forma de amido, nos cloroplastos, ou é transferida ao citossol e convertida nos carboidratos solúveis, sacarose e sorbitol (Quick \& Schaffer, 1996). Somente pequenas quantidades de outros carboidratos são encontrados, como rafinose, estaquiose e mioinositol (Salisbury \& Ross, 1992).

O desenvolvimento do fruto do pessegueiro depende de sua capacidade para atrair carboidratos pela fotossíntese (Faust, 1989). As relações hormonais são, em grande parte, diretamente responsáveis pelo sucesso da frutificação. A fixação do fruto à planta depende do balanço exato entre auxinas, giberelinas, citocininas e etileno (Westwood, 1978).

Não há regra para a poda, sendo necessário, antes de tudo, bom-senso e conhecimento dos seus princípios e finalidades, e do hábito de frutificação das plantas (Raseira \& Nakasu, 1998).

Assim, o objetivo do presente trabalho foi avaliar a influência da poda de renovação na produção de carboidratos em ramos e raízes do pessegueiro cultivar Flordaprince, nas condições de Piracicaba, São Paulo, bem como sua interação com a qualidade dos frutos.

\section{MATERIAL E MÉTODOS}

O experimento foi conduzido no pomar experimental do Departamento de Produção Vegetal da Escola Superior de Agricultura "Luiz de Queiroz", situado no município de Piracicaba, Estado de São Paulo, cujas coordenadas geográficas são: latitude $22^{\circ} 42^{\prime} 30^{\prime \prime}$, longitude $47^{\circ} 38^{\prime} 00^{\prime \prime}$ e altitude de 564 metros. O clima da região, conforme a classificação de Köppen, é do tipo Cwa: tropical de altitude, com três meses mais secos (junho/julho/ agosto), chuvas de verão e seca no inverno. O tipo do solo da área experimental é classificado como Terra Roxa Estruturada Eutrófica, horizonte A moderado sobre textura argilosa, correspondendo ao Argissolo Vermelho eutrófico, de acordo com o Sistema Brasileiro de Classificação de Solos da Embrapa (Embrapa, 1999).

Utilizou-se a cultivar Flordaprince, pessegueiro originário da Flórida, Estados Unidos, que encontrou boa adaptação nas condições climáticas de inverno brando do Estado de São Paulo.

As mudas enxertadas em pessegueiro 'Okinawa' foram transplantadas em agosto de 2001 . O espaçamento adotado foi de 3,0 X 1,2 metros, correspondendo a 2.777 plantas ha ${ }^{-1}$. As plantas foram conduzidas em sistema de líder central, e todas receberam as práticas de irrigação, nutrição, quebra de dormência, tratamentos fitossanitários e desbrotas, práticas estas normalmente utilizadas. Todas as plantas foram submetidas à poda de frutificação, na fase de dormência, no mês de junho.

$O$ experimento constou de três tratamentos: $O$ tratamento 1 consistiu na realização da poda de renovação, no qual se fez a supressão de todos os ramos da planta, que produziram ou não, após a colheita. No tratamento 2 , as plantas não passaram pela poda de renovação, e foi realizado o controle da ferrugem, não ocasionando a desfolha. No tratamento 3 , não foi realizada a poda de renovação, assim como o controle fitossanitário, propiciando o ataque da ferrugem e, portanto, a ocorrência de desfolha.

As plantas que não sofreram a poda de renovação, receberam poda verde onde foram suprimidos apenas os ramos que produziram, as brotações em excesso e/ou mal posicionadas, de acordo com Borba (2002).

A quebra de dormência ocorreu nos dois anos do experimento, no início do mês de junho. Foi aplicada uma solução de cianamida hidrogenada a $0,5 \%$, (produto comercial Dormex ${ }^{\circledR}$ - $49 \%$ de ingrediente ativo). 
O delineamento experimental utilizado foi em sete blocos ao acaso, com 3 tratamentos e 4 plantas por parcela.

Para cada tratamento e repetição, foi medido o crescimento de 4 ramos por planta, a cada 10 dias após a brotação. Os ramos eram, na sua maioria, localizados na altura mediana, aproximadamente a 1,50 m do solo. A medição dos ramos foi feita com o auxílio de uma régua graduada em centímetros, e o comprimento e o diâmetro de dois frutos por ramo a cada 10 dias, utilizando-se de um paquímetro digital.

O peso médio dos frutos foi determinado pelo peso total de frutos colhidos por planta, dividido pelo número de frutos. $\mathrm{O}$ comprimento e o diâmetro médio foram avaliados em 10 frutos de cada planta, por ocasião da colheita, com o auxílio de um paquímetro digital.

A cor da casca foi determinada em duas posições do fruto, utilizando o equipamento Minolta Chroma Mater, sendo os resultados expressos como valor L a b. Esta avaliação foi realizada em 5 frutos de cada planta.

Para a determinação do teor de sólidos solúveis totais SST ( ${ }^{\circ}$ Brix), utilizou-se uma gota de suco puro de cada amostra colocada sobre o prisma de um refratômetro de mesa marca ABBÉ. A leitura foi feita com correção da temperatura para $20^{\circ} \mathrm{C}$. O suco foi extraído de 5 frutos por parcela (4 plantas).

Foram determinadas as concentrações de carboidratos não-estruturados em raízes e ramos, a cada 45 dias, a partir da poda de renovação, segundo a metodologia de AOAC (2000). As amostras foram mantidas em estufa até atingirem peso constante, moídas e levadas para determinar os níveis de carboidratos nos tecidos vegetais. Para essa avaliação, foi considerado apenas o efeito da poda de renovação.

Os resultados foram submetidos à análise de variância, e a comparação entre médias foi feita através do teste de Tukey, a $5 \%$ de significância, utilizando o programa ESTAT - Sistema para Análises Estatísticas (Versão. 2.0), Unesp/ FCAV, Câmpus de Jaboticabal.

\section{RESULTADOS E DISCUSSÃO}

Verificou-se amplitude muito grande com relação ao tamanho dos ramos, que variaram entre 10 a $60 \mathrm{~cm}$. Resultados estes já relatados por diversos autores, que classificaram os ramos de acordo com a distribuição e o número das gemas de flor em: mistos, brindilas, dardos ou ladrões. O crescimento dos ramos deu-se de forma praticamente linear nos primeiros 60 dias de avaliação, sendo que, em torno de 65 dias, a maioria havia cessado seu crescimento (Figura 1). Borba (2002), estudando o crescimento de ramos na cultivar Ouromel 2, no período de verão, registrou a parada de crescimento por volta dos 45 dias. Esse período mais prolongado, observado no presente trabalho, pode ser justificado por se tratarem de cultivares diferentes, avaliações realizadas em épocas distintas e/ou devido as plantas utilizadas nesse experimento serem mais jovens, com cerca de 3 anos, se comparadas às utilizadas pelo autor, com cerca de 5 anos.

Os resultados dos valores obtidos quanto à produção, expressa em $\mathrm{kg}$ de frutos por planta e número de frutos por planta, nos diferentes tratamentos, apresentam-se na Tabela 1 . O tratamento 2 proporcionou maior produção de frutos por planta, bem como maior número de frutos por planta, quando comparado com os demais tratamentos. Hadlich \& Marodin (2004) observaram redução da frutificação devido às podas excessivas após a colheita, principalmente em plantas jovens e vigorosas. Contudo, Marini (1985), ao estudar podas na dormência e podas de verão, não constatou nenhuma diferença na produção. Entretanto, Nienow (1997) constatou que a poda de renovação realizada no final da primavera aumentou a produção de frutos por planta.

O tratamento 3 apresentou um desempenho intermediário, não diferindo estatisticamente dos outros tratamentos. Isso demonstra que a presença de folhas no período após a colheita é de fundamental importância para que a planta continue realizando fotossíntese e acumulando reservas que serão utilizadas nos ciclos seguintes.

Verifica-se, na Tabela 2, que não houve efeito significativo dos tratamentos sobre o peso médio, comprimento e diâmetro dos frutos. Resultados que concordam com Marini (1985) que, estudando podas de inverno e de verão, não encontrou diferenças com relação ao tamanho dos frutos. Também o teor de sólidos solúveis e a coloração dos frutos não foram afetados pelos tratamentos.

Nas Figuras 2 e 3, observa-se que a concentração de carboidratos oscilou durante o ciclo das plantas, de acordo com a época de amostragem. As raízes apresentaram maiores teores de carboidratos em relação aos ramos, independentemente do tipo de poda realizada e da época de amostragem, conforme também verificou Borba (2002).

Constatou-se que ocorreu elevação na concentração de carboidratos, nas raízes e ramos, no mês de agosto, quando as plantas estavam em plena frutificação, momento em que as reservas estavam sendo disponibilizadas para atender à demanda necessária ao crescimento de frutos e de ramos. Entretanto, esperava-se que o pico de concentração de carboidratos nos ramos (Figura 3) coincidisse com uma queda dos teores de carboidratos nas raízes (Figura 2), fato que não foi observado. Provavelmente, o aumento na concentração de açúcares nas raízes pode ter ocorrido em virtude de as plantas possuírem uma reserva de amido suficientemente grande para suprir a demanda de carboidratos dos ramos, sem ocorrer a queda nos teores contidos nas raízes.

Houve diminuição na concentração de carboidratos nos ramos, no mês de agosto, a qual está relacionada à presença de frutos e ramos em crescimento, os quais são fortes drenos. Logo após a colheita, ocorreu aumento na concentração de carboidratos, nas raízes e ramos, uma vez que os frutos, principais drenos, foram retirados das plantas.

As oscilações não-significativas dos teores de carboidratos, no período de dezembro a maio, podem estar relacionadas a surtos de crescimento do sistema radicular. Segundo Faust (1989), a periodicidade do crescimento do sistema radicular depende, em grande parte, do crescimento da parte aérea e da carga de frutos da planta. $O$ final do pico de crescimento inicial, usualmente, coincide com o início do crescimento da parte aérea, durante ou após o florescimento, e o segundo surto de 
crescimento do sistema radicular inicia-se assim que o crescimento da parte aérea cessa.

TABELA 1- Produção e número de frutos por planta de pessegueiro cultivar Flordaprince, nos diferentes tratamentos. Piracicaba-SP, 2004

\begin{tabular}{lcc}
\hline \multicolumn{1}{c}{ Tratamento } & Produção (kg.planta $\left.{ }^{-1}\right)$ & No de frutos por planta $^{\circ}$ \\
\hline Com poda de renovação & $1,34 \mathrm{~b}$ & $28 \mathrm{~b}$ \\
Sem poda de renovação e com controle da ferrugem & $4,27 \mathrm{a}$ & $100 \mathrm{a}$ \\
Sem poda de renovação e sem controle da ferrugem & $3,39 \mathrm{ab}$ & $66 \mathrm{ab}$ \\
\hline \multicolumn{1}{c}{$\mathrm{CV}(\%)$} & 46,28 & 41,97
\end{tabular}

- médias seguidas pela mesma letra na coluna não diferem estatisticamente, pelo teste de Tukey, a $5 \%$ de probabilidade.

TABELA 2 - Características físicas e teor de sólidos solúveis totais de pêssegos cultivar Flordaprince nos diferentes tratamentos. Piracicaba-SP, 2004.

\begin{tabular}{|c|c|c|c|c|c|c|}
\hline \multirow[b]{2}{*}{ Tratamento } & \multirow{2}{*}{$\begin{array}{l}\text { Peso Médio } \\
\text { (g.fruto }^{-1} \text { ) }\end{array}$} & \multirow{2}{*}{$\begin{array}{c}\text { Comprimento } \\
(\mathrm{mm})\end{array}$} & \multirow[b]{2}{*}{$\begin{array}{c}\text { Diâmetro } \\
(\mathrm{mm})\end{array}$} & \multirow[b]{2}{*}{$\begin{array}{l}\text { SST } \\
\left({ }^{\circ} \text { Brix }\right)\end{array}$} & \multicolumn{2}{|c|}{ Ângulo de Cor } \\
\hline & & & & & $\begin{array}{c}\text { Face } \\
\text { exposta }\end{array}$ & $\begin{array}{l}\text { Cor de } \\
\text { fundo }\end{array}$ \\
\hline Com poda de renovação & $47,8 \mathrm{a}$ & $24,84 \mathrm{a}$ & 23,22 & $4,68 \mathrm{a}$ & $47,37 \mathrm{a}$ & $119,61 \mathrm{a}$ \\
\hline $\begin{array}{l}\text { Sem poda de renovação e com } \\
\text { controle da ferrugem }\end{array}$ & $42,7 a$ & $33,59 \mathrm{a}$ & $32,17 \mathrm{a}$ & $6,30 \mathrm{a}$ & $65,31 \mathrm{a}$ & $118,35 \mathrm{a}$ \\
\hline $\begin{array}{l}\text { Sem poda de renovaçã o e sem } \\
\text { controle da ferrugem }\end{array}$ & $51,3 \mathrm{a}$ & 33,12 a & $32,27 \mathrm{a}$ & $6,67 \mathrm{a}$ & $62,24 a$ & $116,26 \mathrm{a}$ \\
\hline $\mathrm{CV}(\%)$ & 23,78 & 20,26 & 20,01 & 19,65 & 19,88 & 17,77 \\
\hline
\end{tabular}

- médias seguidas pela mesma letra na coluna não diferem estatisticamente, pelo teste de Tukey, a $5 \%$ de probabilidade.

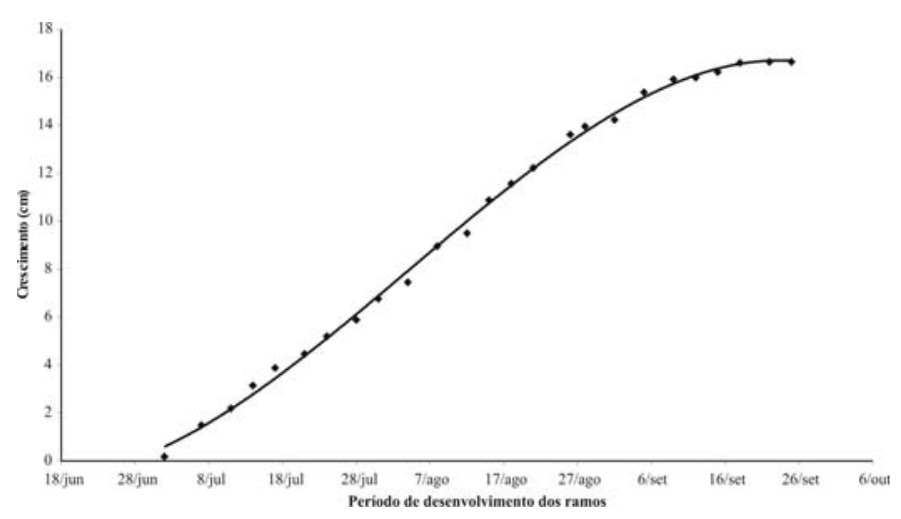

FIGURA 1 - Crescimento médio dos ramos de pessegueiro cultivar 'Flordaprince', após a poda de produção. Piracicaba-SP, 2004.

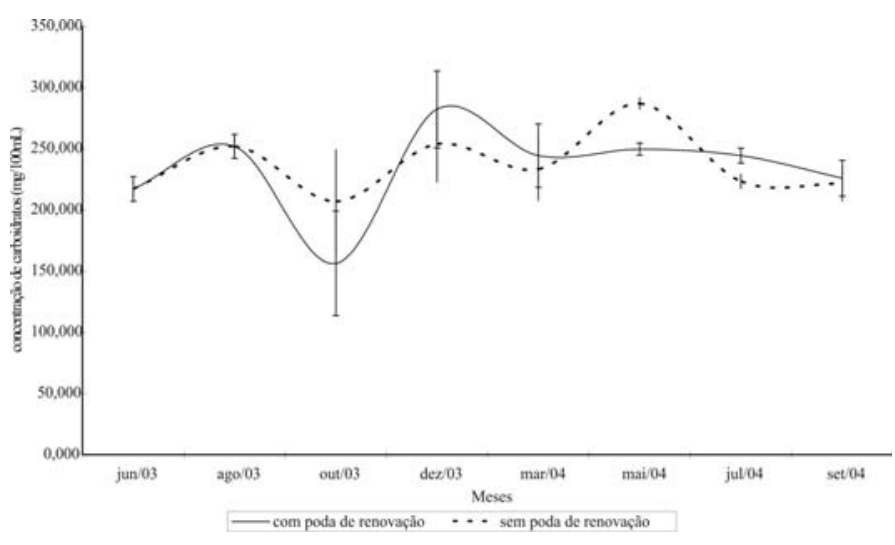

FIGURA 2 - Teores de carboidratos nas raízes das plantas, com e sem poda de renovação, de pessegueiro cultivar Flordaprince. Piracicaba-SP, 2004.

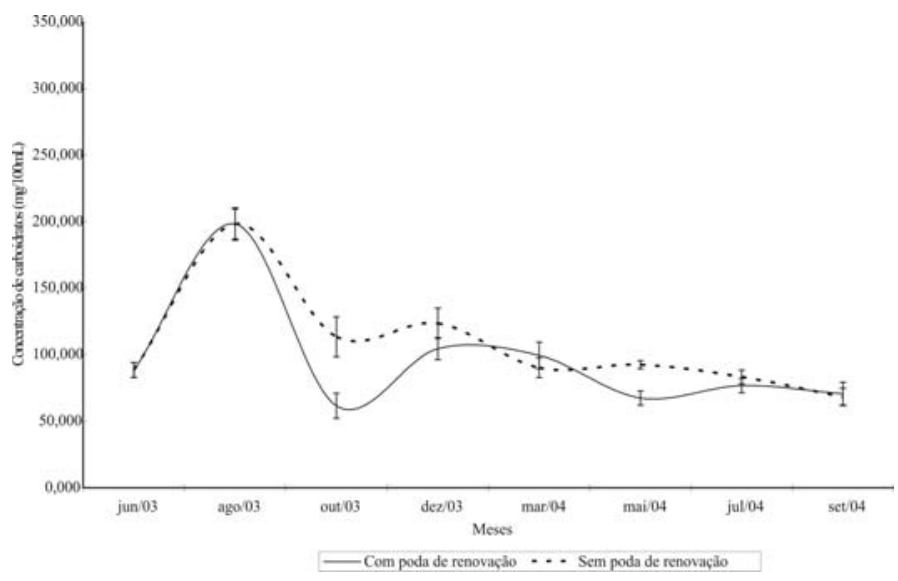

FIGURA 3 - Teores de carboidratos nos ramos das plantas, com e sem poda de renovação, de pessegueiro cultivar Flordaprince. Piracicaba-SP, 2004.

\section{CONCLUSÕES}

1-A concentração de carboidratos solúveis nas raízes e ramos varia ao longo o ciclo do pessegueiro.

2-Os teores de carboidratos solúveis nas raízes são sempre superiores àqueles encontrados nos ramos.

3-A poda de renovação, realizada no primeiro mês após a colheita, provoca queda na produção do pessegueiro CV. Flordaprince.

\section{REFERÊNCIAS}

AOAC. A Official Methods of Analysis of AOAC Internacional. $17^{\text {th }}$ ed. Maryland; AOAC Internacional, 2000. 818p.

BORBA, M.R.C. Teores de carboidratos em pessegueiros (Prunus persica (L.) Batsch) submetidos a diferentes tipos de 
poda. 2002, 51f. Dissertação (Mestrado)- Escola Superior de Agricultura "Luiz de Queiroz", Universidade de São Paulo, Piracicaba, 2002.

EMBRAPA. Sistema brasileiro de classificação de solos. Brasília: Embrapa Produção de Informação; Rio de Janeiro: Embrapa Solos, 1999.412p.

FAUST, M. Physiology of temperature zone fruit trees. New York: John Wiley, 1989.338p.

FRANCISCONI, A.H.D.; BARRADAS, C.I.N.; MARODIN, G.A.B. Efeito da poda verde na qualidade de fruto e na produção do pessegueiro cv. Marli. Pesquisa Agropecuária Brasileira, Brasília, v.31, n.1, p.51-54, 1996.

HADLICH, E.; MARODIN, G.A.B.; Poda e condução do pessegueiro e da ameixeira. In: MONTEIRO, L.B. et al. Fruteiras de caroço: uma visão ecológica. Curitiba: UFPR, 2004.p.97-118.

MARINI, P.M. Vegetative growth, yeld and fruit quality of peach as influenced by dormant pruning, summer pruning and summer topping. Journal of the American Society for Horticultural Science, Alexandria, v. 110, n.2, p. 133-139, 1985.

NIENOW, A.A. Comportamento morfológico, fenológico e produtivo de cultivares de pessegueiro (Prunus persica $\mathrm{L}$. Batsch), submetidos a poda de renovação após a colheita, na região de Jaboticabal/SP. 1997. 179 f. Tese (Doutorado) Faculdade de Ciências Agrárias e Veterinárias, Universidade Estadual Paulista, Jaboticabal, 1997
OJIMA, M.; CAMPO-DALL'ORTO, F.A.; RIGITANO, O.; TOMBOLATO, A.F.C.; BARBOSA, W. Melhoramento da nectarina em São Paulo. I. Cruzamento de 1970: seleção nas gerações F1 e F2. Bragantia, Campinas, n.42, p.1-14, 1983.

QUICK, W.P.; SCHAFFER, A.A. Sucrose metabolism in source and sinks. In: ZAMSKI, E.; SCHAFFER, A.A. Photoassimilate distribuition in plants and crops: source-sink relationship. New York: Marcel Dekker, 1996. p.115-156.

RASEIRA, M.C.B.; NAKASU, B.H. Cultivares: descrição e recomendação. In: MEDEIROS, C.A.B.; RASEIRA, M.C.B. A cultura do pessegueiro. Brasília: Embrapa. SPI, 1998. p.29-97.

ROITSCH, T.; BALIBREA, M.E.; HOFMANN, M.; PROELS, R.; SINHA, A.K. Extracellular invertases: metabolic enzyme and metabolic protein. Journal of Experimental Botany, Lancaster, v.54, n.382, p.513-524, 2003.

SALISBURY, F.B.; ROSS C.W. Plant physiology. California: Wadsworth Publishing Company, Belmont, California, 1992.682p

WESTWOOD, M.N. Temperature-zone pomology. San Francisco: W.H. Freeman, 1978.428p. 